\title{
Automation for building performance and maintenance efficiency
}

\author{
Nuno D. Cortiços \\ Centro de Investigação em Arquitectura, Urbanismo e Design, Faculdade de Arquitectura, Universidade de Lisboa, R. Sá Nogueira, 1349-063 \\ Lisboa, Portugal
}

\begin{abstract}
In Western Europe, $80 \%$ of buildings will continue to exist beyond 2050. Almost all, 98-99\%, need to be updated and maintained in conformity with the requirements to new buildings, designated as nearly zero-energy buildings (nZEBs). In principle, buildings with modern superstructures have a potential lifespan of over 120 years, without compromising safety. Considering materials, labor, logistics, pollution, gas emissions, energy involved in the construction and assuming its heritage value, it is recommended a full modernization of buildings to assure their utility in favor of communities. This research focuses on reaching the maintenance efficiency and buildings performance, without increasing the costs.

The Model is designed to measure and anticipate the degradation of buildings, in three steps. Starting with a network of active sensors, embedded and non-embedded in layers of components and subcomponents, which survey and monitor the condition of the building systems. Those will provide accurate data for computational analysis (first step) and quantify and qualify the viability of construction systems with the highest impact on building performance. The information supports the managers' decisions (second step), before compromising the materials and the constructive solutions, saving work time, reducing maintenance costs, and assuring the highest performance, while preserving user's comfort. And promote a rapid and specific response to stop early anomalies (third step), by obtaining an outsourced contract to respond to daily basis needs (and not tasks) with specialized technicians.

The information collected will help to determine policies, anticipate anomalies, plan proper maintenance, ranking investments and intervene on marked systems. The three-step model aims for a reduction of natural resources usage, a decrease of human impact, to increase the efficiency and to improve the performance of the building stock.
\end{abstract}

(C) 2018 The Authors. Published by Diamond Congress Ltd., Budapest University of Technology and Economics Peer-review under responsibility of the scientific committee of the Creative Construction Conference 2018.

Keywords: autonomous building maintenance; computational maintenance model; facility management; building maintenance sensors; building performance; building user experience; energy efficiency in building

\section{Introduction}

The research aims to design a three-step maintenance model to improve building usage on a low-cost basis; by understanding the contribution of surveying buildings systems to slow the aging and degradation processes. To apply nZEBs concept of the building stock, based on a network of active sensors to measure the condition of passive systems. And support renovation for those compromised through the best contemporary materials, and cutting-edge building solutions, gathering comfort, efficiency, and more straightforward maintenance; all in favor of the managers' decisions, Facility (FM) and (or) Property (PM).

In Western Europe, $80 \%$ of buildings will continue to exist beyond 2050. Almost all, 98-99\%, need to be updated and maintained in conformity to the requirements for new buildings, designated as nearly zero-energy buildings (nZEBs). The European Union aims to reduce 80 to $95 \%$ carbon dioxide $\left(\mathrm{CO}_{2}\right)$ emissions from the construction sector [1]. Therefore, the definition of strategic guidelines is essential to ensure, foreseen, higher energy necessities, and the development of cleaner energy sources: locally produced, manageable by consumers, and inexpensive (when compared to fuel fossil standards).

Since 1980 many existing buildings adopted passive solar design, and Passive House (PH) concept to gather higher efficiency by lowering the energy consumption, from $70 \%$ to $90 \%$ or $15 \mathrm{~kW} / \mathrm{m}^{2}$.year. More would be possible, 
assuming today's knowledge and technologies, but due to players conservatism, new approaches were unconsidered, especially when the new is more expensive and unproven. Nevertheless, when applied to buildings, savings of $65 \%$ to $90 \%$ can be achieved, if efficient acclimatization is used, comparing the initial consumptions to the renovated [2].

Nowadays, the European Union (EU) is one of the driving forces in the pursuit of the reduction of $\mathrm{CO}_{2}$ emissions. Europe, a stable Continent since World War II, has a vast building stock with high architectural value, which deserves to be properly maintained and updated to meet future policies, considering current environmental concerns. To accomplish this goal, the EU established an observatory, ZEBRA2020, responsible for promoting and surveying the implementation of nZEBs (nearly zero-energy buildings). However, its efforts are directed to new buildings.

In EU countries, $40 \%$ of the buildings were built before 1960 and $90 \%$ before 1990 [3], consuming $40 \%$ of the available energy (55\% as electricity) and emitting $36 \%$ of $\mathrm{CO}_{2}$.

The $\mathrm{PH}$ approach is being used to increase building efficiency, to comply with the Paris Agreement (PA) guidelines, and ensure that $2^{\circ} \mathrm{C}$ above pre-industrial levels are not exceeded. To accomplish this goal, EU intends to reduce $40 \%$ of $\mathrm{CO}_{2}$ by 2030, when compared to 1990 values; $1 / 3$ of the effort must be made by buildings renovation [4].

\subsection{Question}

In the EU, new building construction to replace existing ones is around $1 \%$ per year, considering all stock. The new buildings' market is lethargic, creating the opportunity for renovation, to meet the PA goals. ${ }^{1}$ Those operations represent $57 \%$ of the Sector's revenue, but only 1 to $2 \%$ of existing buildings improve the energy efficiency as established for new buildings [4]. By 2020, it is intended to grow the renovation up to 2-3\% (the highest percentage considers public buildings), improving to $20 \%$ the building stock energy efficiency, and $27 \%$ by $2030 .^{2}$

Past construction technology tends to be less energy efficient when compared to the newer: meaning higher energy consumption and therefore more $\mathrm{CO}_{2}$ emissions [5]. Nevertheless, not all of the existing buildings have the same renovation potential to achieve the required efficiency, depending on its owner's usage intentions and financial capacity, construction potential, and architecture nobility [6]. The investment versus reimbursements, based on potential gains - energy reductions, and maintenance, life cycles and lifespan — are achievable in less than 30 years [7].

Construction on developed countries, as a fundamental need, is continuously surveyed, analyzed and improved to meet high-quality life standards. The American and Western Europe market represent $53 \%$ of all efficiency investments. For the US, the Sector projected expenditures from US\$ 7.4 trillion in 2010 to US\$ 8.5 trillion in 2015 and US\$ 10.3 trillion in 2020, at 2010 constant prices and exchange rates [8]. A recent survey $(2015-2017)^{3}$ shows that the Sector is highly committed to efficiency efforts in 'building designs and construction' and 'building operations and maintenance': $77 \%$ responded 'very highly preferred' and 70\% 'highly preferred', respectively; and, also, the industry's transparency in pursuing the buildings' efficiency, $48 \%$ of the surveyed pointed out a growth of $10 \%$ for next 12 months (2015-2016). But the Industry also recognized its 'higher initial cost' as assumed per 69\% of respondents (2015). In the European Union (EU), the Industry contributed to 9\% (EUR 13 trillion) for the Gross Domestic Product (GDP), ensuring 10,46\% (18 million) of total available jobs. While it ensures the economic growth, the cut of $\mathrm{CO}_{2} \mathrm{emissions}$, as it moves away from the fuel fossils [9]. The renovation market in the EU, in 2015, was worth approximately EUR 109 billion, assuring 882,900 jobs; it is, at least, questionable not to invest in building stocks' maintenance by applying the latest technologies, most produced locally.

The construction industry plays a significant role in the global economy, however it is one of the most resilient to adopt cutting-edge technology, in both construction and maintenance. In spite of that, automation is emerging in new buildings, and high-quality renovations; both enforcing measures to control energy (e.g., lighting, HVAC, ventilation, plumbing and conveying).

\subsection{Background}

Industries turn to technology, by investing and researching solutions, when the lack of safety and maintenance become public issues. While, 'active' surveillance can play an important role in diminishing questions raised by current

\footnotetext{
${ }^{1}$ The Energy Efficiency Directive (EED) (2012/27/EU) defines building stock as "the single biggest potential sector for energy savings... crucial to achieving the Union objective of reducing greenhouse gas emissions by $80-95 \%$ by 2050 compared to 1990 ."

${ }^{2}$ On October 27, 2017, the European Commission announced the allocation of $€ 30$ billion on the Horizon 2020, a European Union research and innovation funding program, between 2018-2020, including $€ 2.7$ billion to establish a European Innovation Council.

${ }^{3}$ Database - Market Reports Store [Internet]. prnewswire.com. 2015 [cited March 12, 2018]. Available from: https://www.prnewswire.com/
} 
requirements (on PA perspective) for energy efficiency on the building stock; addressed by recent technology to solve issues, as a standard approach since the World War II.

"ENERGY STAR" and "Leadership in Energy and Environmental Design" (LEED) were developed, more than two decades ago, as tools to measure energy efficiency and sustainability. Instantly, gathering much public interest which promoted to the green movement. New solutions have been implemented by professionals, designers and operators, to accommodate the consumers' needs and label buildings according with their ecological footprint.

Today, some automation systems are available, offering immediate adjustment to the maintenance schedule, but limited to powered equipment. The goals are: systems' efficiency, decrease of energy consumption, costs reduction related to operations and activities, improvement of equipment efficiency and infrastructure life-cycle.

Two systems are frequently used by the Sector: Building Automation System (BAS), embodies the control and management of heating, ventilation and air conditioning, lighting and others, and Building Management Systems (BMS), with a more extensive automatic surveillance, managing BAS and gather other systems, like water supply, security and fire control [10]. BMS are adaptable to different buildings scales and functions, managed by a single workstation or by an operations center, but they need a dedicated network plus software, to minimize tasks and complexity for chief engineers and building operators. However, BMS/BAS tend to be expensive when compared to other systems, and don't gather analytic insight, relying on facility manager's judgment and decisions. Systems based on electric infrastructure, as Energy Management Software (EMS), are easier to install and operate, affordable when alongside BMS/BAS and opened to third parts' resources, gathering outside conditions (wind speed, temperatures, humidity, pollution, et cetera) on time, sharing information with nearby buildings; and, adapting to the weather forecast. The EMS is adjustable to different building scales and institution needs and can work alongside BMS/BAS, increasing overall savings, and optimizing operations.

The TechNavio forecast to improve active systems' efficiency, in June 2017, by the buildings' automation will grow, by 2021: above $9 \%$ on software; and 11\% on control systems, based on wireless sensors. [11] Automation is a trend, and the Sector shows a propensity for its use on future products, but its significant impact depends on the building stock managers decisions.

Nowadays, buildings maintenance's researchers subscribe to the need of computational support to segregate the information workflow, showing the viability of systems regarding the condition, the life-cycles, and the lifespan [12][13][14][15][16]. Still, those limited to energy consumption on active systems. The passive systems energy losses are neglected: not attending real performance condition or upgrades towards nZEBs directives (as intended for the EU new buildings).

Building Information Modeling (BIM) researchers support the introduction of Information Technology (IT) in the "architectural, engineering, construction and owned-operation" (AECO) industry to increase energy efficiency, productivity, and profitability [17][18]. Nevertheless, the quoted only supports the improvements on new building operations and, as disclosed above, built in urban areas in developed countries, taking into consideration the population growth or a new economic paradigm.

At present, the focus of the industry is to produce buildings with greater energy efficiency, overseeing equipment such as HVAC [19] [20], lighting [21] and energy consumption management [22] [23].

Today, the focus of the industry is to produce buildings with greater energy efficiency, by overseeing the equipment, such as HVAC [19][20], lighting [21] and energy consumption management [22][23]. Nevertheless, active systems are responsible for less energy consumption $\left(\mathrm{kWh} /\left(\mathrm{m}^{2}\right.\right.$.annual $\left.)\right)$ when compared to passive's, according to data provided by Fachinstitut Gebäude-Klima e.V., 2007 [24].

Building external enclosure allows potential energy losses and requires high maintenance (various finishes over multiple layers). The thermal performance can be improved if a correct technological approach is considered; by addressing, e.g., the shortcomings/insufficiencies of the insulation, humidity presence, and the air permeability through finishing and layering systems [25]. When simple sum with active systems, passive systems have a broader spectrum on constructive solutions, of different designs style, shapes and materials and layering composition, and can be responsible for a significant reduction of energy consumption, up to 50\%. At the same time, when combined they can achieve a reduction of energy consumption up to $60 \%$ : e.g., strategies for heating or cooling in line with external enclosure performance. [26]

Buildings lifespan is often divided in the three major phases: design, construction and operation [27]. Maintenance works cannot end, otherwise, the buildings' performance and their operations get compromised. To control the aging and external factors it is essential to maintain a close surveillance, and IT can play an important role, alerting to the compromised systems' performance. Although, today, they are limited to design and construction phases [28][29]. To 
perceive the energy efficiency, the focus must be on higher costs [30] and with the environmental impact [31] along the operation phase, mainly on maintenance contributions.

\subsection{Possible Approach}

The standard maintenance plans, imposed by law, are produced by the designers gathering technical information shared by developers and suppliers of materials, constructive solutions, and power equipment, to be provided to owners and investors to manage the buildings during the first decade;. During the buildings' warranty period, FMs and PMs technicians monitor the systems' condition. Nevertheless, the condition evaluation depends on the technical skills and experience of the technicians. For a correct perception, it is advisable to resort to three technicians (at minimum) to reach the true condition's analysis. Such number of technicians represent a high cost for institutions, and are difficult to justify, especially when there is an excellent global condition perception. Also, the reported data is exposed to externalities such as interpretation, communication, coordination, and achievement. Managers will consider the anomalies report, and repair costs; a decision will depend on several issues: e.g., assurance, awareness, financial capacity, and investment priorities, to react before future expenses. The high maintenance costs are, potentially, linked to under-evaluations, resulting in future complex tasks, but the over-evaluation also diminishes systems life expectancy
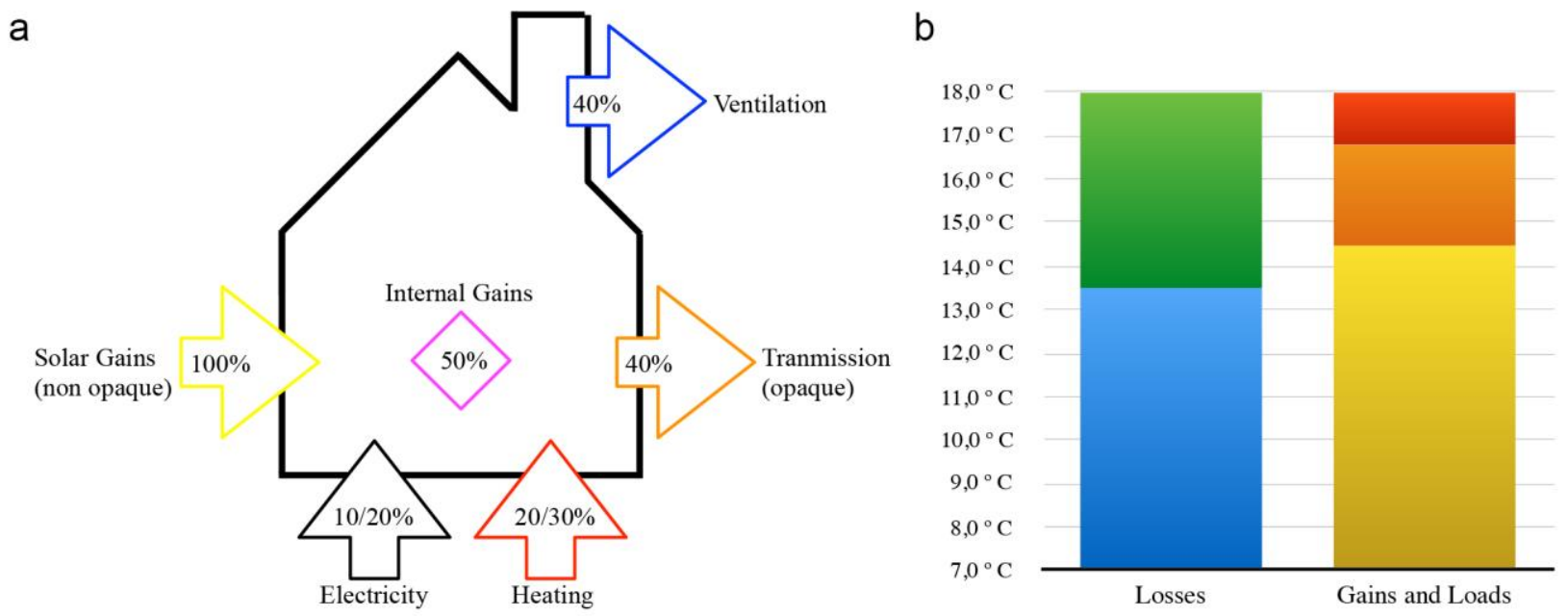

by neglecting minor repairs.

Figure 1 - (a) Regenerative percentage of the heat recovery [9]; (b) Average EU Heat balance for space heating 2010 (VHK 2014) [32].

As shown and pursued by this research, a wide a range of active sensors can contribute to maintain building stocks at the highest level of performance, as demanded by the PA: in high energy efficiency, low-cost maintenance, with a spaced schedule and less demanding. The System intends to survey a specific building aging by analyzing and comparing it to others. So, maintenance is adjusted with third party contributions (anomalies' reports and solution tasks), working with a global network; the external database will define the optimization models and the best approach.

Buildings depend on vital systems to assure usability, comfort and performing without compromising the overall efficiency; as described on "Facilities Maintenance Management Model," by Igal M. Sohet and Sarel Lavy, marginal condition (above safety) 80\%. Building systems are complex and deeply connected, and to monitor them it is mandatory to resort to a spectrum of sensors and related technology, gather by Internal Systems (communication tools, hardware, software, and databases) and External Systems (defining ideal models). These tools already exist and are commonly applied, in other industrial products, assuring precise maintenance and high-performance during all lifespan.

\subsection{Manuscript Structure}

This manuscript presents an overlay monitoring system to increase the performance of the buildings' stock in 
developed countries. The possibility of assessing the condition of the passive system, during the building's lifespan, shows the importance of envolving IT and AI in the future of building maintenance; by preventing, reacting and reducing the impact of degradation. The effect of the running costs to property owners, in energy and maintenance expenditure, is, also, overseen. In the end, it is presented the research results and discussion of the introduced systems, as a significant contribution to achieve the Paris Agreement goals, driven by the nZEB concept. As a conclusion, focusing on the building life experience to reach the highest performance possible, at the same time, ensuring the lowest servicing costs.

\section{Methodology}

\subsection{Maintenance Adviser System (MAS) and Automatic Maintenance Surveillance (AMS) Design}

The Maintenance Adviser System (MAS) and Automatic Maintenance Surveillance (AMS) are two mechanisms that work side-by-side to improve building stock renovation. MAS is a master server that confirms AMS outcomes, in order to provide intelligence renovation advise to property management teams, as exposed in Figure 2:

1) Surveillance Network;

2) Sharing Data (MAS between AMS);

3) External Contributions;

4) Measured Condition;

5) Visual Inspection and Testing Equipment by FM personnel and, if assurable by in-house capacity, underwork (Final Stage I); If not,

6) Reported Under Performance System Condition;

7) Delayed, if not accepted;

8) Acquisition process, is accepted;

9) Outsource Contract; and,

10) Underwork (Final Stage II).

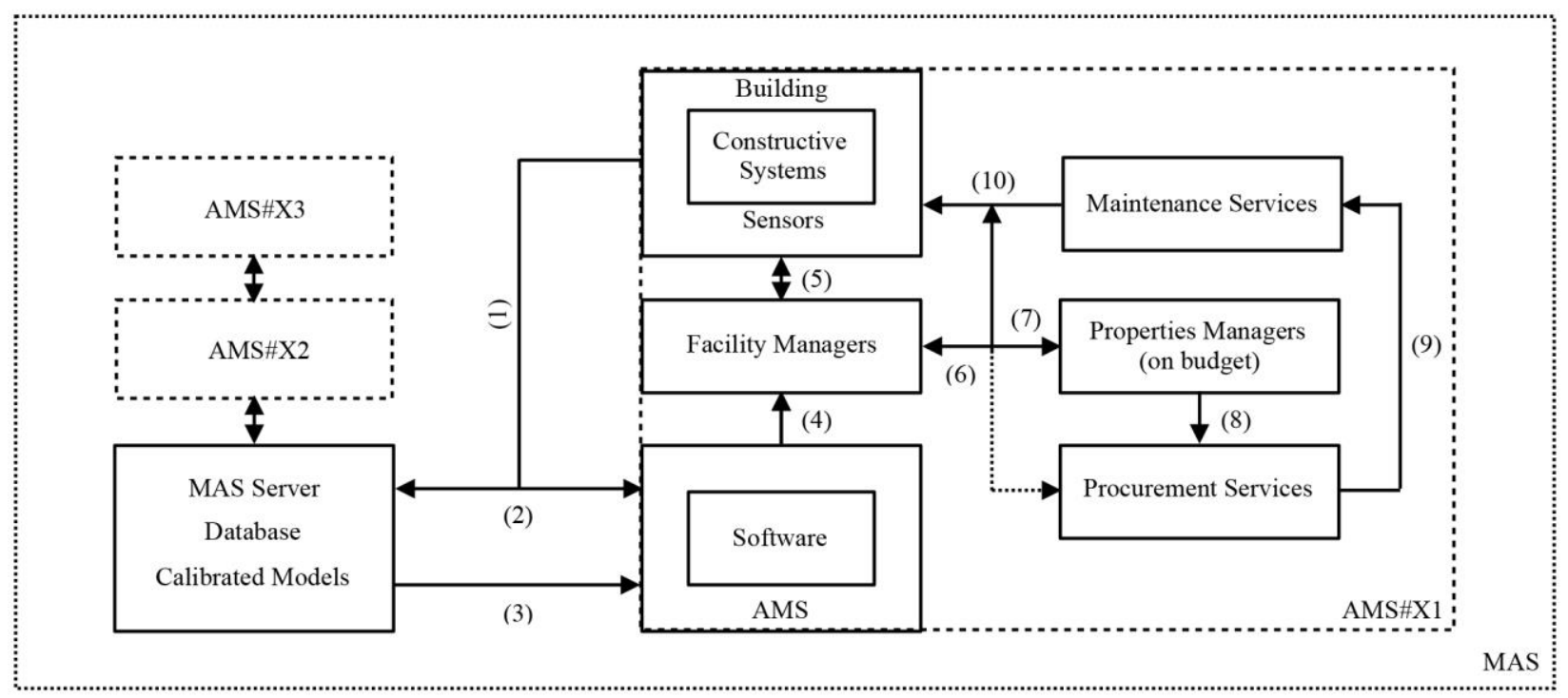

Fig. 2. Maintenance Adviser System (MAS) and Automatic Maintenance Surveillance (AMS)

Any existing building will share its technical systems with others, with similar characteristics. And, if that connects to a local surveillance system, it is possible to compile data and measure aging and other external contribution rates. Building systems will need to be categorized taking into consideration building's systems characteristics. In order to be monitored, a building requires the installation of a wireless sensors network, connected to local WI-FI, to survey its 
condition and allow AMS' processing, compiling data shared with the Global Automatic Surveillance Advisor System (MAS) to certify the collected info.

The MAS system collects renovation data, on similar building stocks, and monitors their performance on-site, to support future advise on similar needs (AMS\#X1/X2/X3 ...). Performance has, on both systems, multidimensional importance in ensuring the renovation's quality and strength, even in low-cost maintenance and with spaced cycles, as it guarantees the increase of energy efficiency towards nZEBs. To achieve an in-depth renovation, it is mandatory to fulfill a few milestones as standard high-technology, at reasonable prices, and resort to tested solutions. All in performance favor based on lowest investment and reimbursement on the shortest period.

The AMS action depends on a sensor to read and detect an anomaly and to report it to the external server (1); confirmed by calibrated models (2); and redirected to the AMS server (3). The facility manager's team will receive a report (4) that requires confirmation on-site (5), if favorable, it will be submitted to the property's managers (6/7), after accepted is transferred to procurement services (8). These services will be acquired externally or demanded to the internal maintenance team (9) to proceed with the renovation repairs (10). As above written, the achieved renovation tasks and the further monitoring will feed MAS, which will provide valuable information to address similar anomalies in building systems.

\subsection{Sensor Network on Passive Building Systems}

Sensors play a fundamental role in the systems, therefore, must be based on standard technology to maintain a lowprice tag. Since they obtain the condition of passive building systems, it only implies a data input per day to feed AMS. If a system gets compromised, the sensor should alert the property managers and offer pre-uploaded solutions, based on MAS. These solutions derive from other renovations on similar buildings and, more important, they are monitored accordingly with their performance through time. The procurement procedures and the team responsible for the renovation works must be registered (for future consulting), assuring the best results on the forthcoming renovations. ${ }^{4}$

\section{Results and Discussion}

In developed countries, it is difficult to demolish an old building, especially, in the urban environment, without a significant impact on the cities daily life, its users, and businesses. Cities are densely structured, and construction works are expensive and time-consuming, emitting light particles, producing gas emissions, consuming essential resources with impact on urban dynamics, by affecting mobility and overload the supply grids: despite the pursuit for debris recycling [33]. Massive works in confined blocks, surrounded by others, raise potential risks for workers and properties. None the less, there is a tendency for demolishing buildings before exploring all their potentialities [33].

Maintenance embraces the idea of renovation by over-laying increasingly, adding or changing the existing building systems. Other forms of maintenance, like conservation, tend to diminish through the system's lifespan (along with its viability), and rehabilitation will eventually vanish from the Sector. Conservation is profitable in the early stages, but renovation is so dependent on the workforce and time-consuming that, at some point, will be deferred in favor of major construction works.

This research intends to increase the performance and lifespan of today's buildings, by monitoring the passive systems aim and their contribution to the overall efficiency. By adding them to the efforts achieved on the active systems' monitoring, as BMS/BAS and EMS, nowadays [10]. In opposition to those, AMS sensors are designed to communicate directly with the WI-FI network and its hardware/software, in-house [11], and, on a higher level, to cross information with external data systems, like MAS, to read, analyze, and react, based on the performance of similar renovation operations.

BIM's aim for a universal approach to buildings' design and management, but, as established today, fail to spread into existing buildings. Further steps are needed so that BIM will be able to oversee passive systems performance, as aging rate and external impacts on their lifespan. They should work side-by-side with active systems maintenance, ensuring the same care, once both contribute to higher energy consumption, when not properly maintained [17][18]. When passive constructive solutions reach an underperformance condition, the energy consumption increases: with a higher impact on overall costs, demanding a more effort from actives'. The firsts have an extraordinary effect on the user's comfort, therefore, must be on the focus of the PMs teams. [24][25][26]

\footnotetext{
${ }^{4}$ The sensors technological approach will be developed in a future paper.
} 
Building Maintenance Automation is a tool to identify and prevent early stage anomalies while is self-learning from similar conditions; it will benefit properties development and their activities, avoiding downtime and underperformance. All supported by precise data, in real-time, on building systems aging condition: to avoid high energy consumption and reduce building performance or the uncertainty on maintenance expenditures. At the same time, ensuring the maximum outcome, aligning building's lifespan with maximum performance, as driven by environmental goals.

\section{Conclusions}

Building degradation starts on day one. Maintenance can slow down the rate of overall performance lost. Conservation, in the first years, and rehabilitation, later, can maintain a building's condition close to the original. Due to evolution, the systems will get outdated, when considering to the present goals. The solution is renovation through the latest building achievements, especially in energy savings. Aimed by the Sector: the automatic renovation of the building systems when under-performing or near the end of their life-cycle.

The Automatic Maintenance Surveillance can help property owners to reach savings, by applying monitoring systems on passive systems and proceeding to 'smart' renovation based on high-tech materials and building solutions tested (available on local markets), and, also, evaluated by the AMS, in previous improvements on similar buildings.

The automation applied to maintenance, on condition monitoring and reparation advisor, fed by a set of digital sensors, embedded and non-embedded in building systems, surveying existent building condition, collecting information to pursue today's energy efficiency goal, can reach the nearly zero-energy buildings (nZEBs) concept. This goal will create a new market share, with a high potential for growth, in maintenance expenditures and activities. In years to come, especially in the most requested properties or with a high economic value, it can translate into an extra revenue to institutions, while it meets the PA guidelines.

The evolution of building maintenance will be assumed by artificial intelligence, as presented above (MAS+AMS). Systems will self-learn if provided with the income directives and policies for buildings maintenance and the new materials and buildings solutions available, assuming the best maintenance decisions aligned with the policy goals.

Maintenance Systems, as MAS+AMS, will get more precise by integrating the incoming building solution characteristics and crossing them with the building stock. They will be able to perceive the scopus of renovation, and after a renovated solution is applied, it will keep on monitoring those performances to be considered on other building stock. Nonetheless, with the collected data is possible to foresee the behavior of those new solutions, in conservation cycles, costs and lifespan.

\section{Acknowledgements}

The author would like to thank: Fundação para a Ciência e Tecnologia (FCT - Portugal) for the financial support to the research project UID/EAT/04008/2013, through the Research Centre for Architecture, Urbanism and Design, Faculty of Architecture, University of Lisbon (CIAUD - Portugal).

\section{References}

[1] European Commission, “The European Construction Sector," pp. 1-16, 2016.

[2] T. Ekström, R. Bernardo, and Å. Blomsterberg, "Cost-effective passive house renovation packages for Swedish single-family houses from the 1960s and 1970s," Energy Build., vol. 161, pp. 89-102, 2018. https://doi.org/10.1016/j.enbuild.2017.12.018

[3] H. H. (W/E C. Laure Itard (OTB), Frits Meijer (OTB), Evert Vrins, "Building Renovation and Modernization in Europe: State of the Art Review," PAN Europe, 2008.

[4] I. Artola, K. Rademaekers, R. Williams, and J. Yearwood, "Boosting Building Renovation: What potential and value for Europe?," 2016.

[5] A. Power, "Does demolition or refurbishment of old and inefficient homes help to increase our environmental, social and economic viability?," Energy Policy, vol. 36, no. 12, pp. 4487-4501, 2008. https://10.1016/j.enpol.2008.09.022

[6] A. Avelin, E. Dahlquist, and F. Wallin, "Effect of different renovation actions, their investment cost and future potential," Energy Procedia, vol. 143, pp. 73-79, 2017. https://doi.org/10.1016/j.egypro.2017.12.650

[7] N. D. Cortiços, "Buildings' Renovation to Improve the Higher Education's Properties Lifespan," manuscript submitted for publication, 2018.

[8] N. R. Council, Advancing the Competitiveness and Efficiency of the U.S. Construction Industry. Washington, DC: The National Academies Press, 2009. https://doi.org/10.17226/12717

[9] P. Moseley, "Practical Approaches to the Building Renovation Challenge," 2016.

[10] M. Manic, D. Wijayasekara, K. Amarasinghe, and J. J. Rodriguez-Andina, "Building Energy Management Systems: The Age of Intelligent and Adaptive Buildings," IEEE Ind. Electron. Mag., vol. 10, no. 1, pp. 25-39, 2016. https://10.1109/MIE.2015.2513749

[11] TechNavio - Infiniti Research Ltd., "Global Building Automation Software Market 2017-2021” London, 2017. 
[12] V. Tarandi, “A BIM Collaboration Lab for Improved through Life Support,” Procedia Econ. Financ., vol. 21, pp. 383-390, 2015. https://doi.org/10.1016/S2212-5671(15)00190-2

[13] Y.-C. Lee, C. M. Eastman, and J.-K. Lee, "Validations for ensuring the interoperability of data exchange of a building information model," Autom. Constr., vol. 58, pp. 176-195, 2015. https://doi.org/10.1016/j.autcon.2015.07.010

[14] M. R. Halfawy, "Municipal information models and federated software architecture for implementing integrated infrastructure management environments," Autom. Constr., vol. 19, no. 4, pp. 433-446, 2010. https://doi.org/10.1016/j.autcon.2009.11.013

[15] P. Li and T. M. Froese, "A green home decision-making tool: Sustainability assessment for homeowners," Energy Build., vol. 150, pp. 421431, 2017.https://doi.org/10.1016/j.enbuild.2017.06.017

[16] Y. Zou, A. Kiviniemi, and S. W. Jones, "A review of risk management through BIM and BIM-related technologies," Saf. Sci., vol. 97, pp. 8898, 2017. https://doi.org/10.1016/j.ssci.2015.12.027

[17]B. Succar, "Building information modelling framework: A research and delivery foundation for industry stakeholders," Autom. Constr., vol. 18, no. 3, pp. 357-375, 2009. https://doi.org/10.1016/j.autcon.2008.10.003

[18]M. Kassem and B. Succar, "Macro BIM adoption: Comparative market analysis," Autom. Constr., vol. 81, pp. 286-299, 2017. https://doi.org/10.1016/j.autcon.2017.04.005

[19] V. L. Erickson et al., "Energy efficient building environment control strategies using real-time occupancy measurements," Proc. First ACM Work. Embed. Sens. Syst. Energy-Efficiency Build. - BuildSys ’09, p. 19, 2009. https://10.1145/1810279.1810284

[20] G. Gao and K. Whitehouse, "The self-programming thermostat: optimizing setback schedules based on home occupancy patterns," Proc. First ACM Work. Embed. Sens. Syst. Energy-Efficiency Build., pp. 67-72, 2009. https://10.1145/1810279.1810294

[21] D. T. Delaney, G. M. P. O'Hare, and A. G. Ruzzelli, "Evaluation of energy-efficiency in lighting systems using sensor networks," in Proceedings of the First ACM Workshop on Embedded Sensing Systems for Energy-Efficiency in Buildings - BuildSys '09, 2009 , p. 61. https://10.1145/1810279.1810293

[22] Y. Agarwal, S. Savage, and R. Gupta, "Sleepserver: A software-only approach for reducing the energy consumption of pcs within enterprise environments," in USENIX Annual Technical Conference, 2010, pp. 22-22. https://www.synergylabs.org/yuvraj/docs/Agarwal-Usenix10SleepServers.pdf

[23] Y. Agarwal, S. Hodges, R. Chandra, J. Scott, P. Bahl, and R. Gupta, "Somniloquy: augmenting network interfaces to reduce PC energy usage," Proc. 6th USENIX Symp. Networked Syst. Des. Implement., pp. 365-380, 2009. https://www.synergylabs.org/yuvraj/docs/Agarwal_NSDI09_Somniloquy.pdf

[24] Handel, C., European Ventilation Industry Association (EVIA), Ventilation with heat recovery is a necessity in "nearly zero" energy buildings, HVAC Journal, Brussels. Available at: http://www.rehva.eu/index.php?id=239 Accessed: 2014-05-28, access on Nov, 6, 2017.

[25] A. Rashwan, O. Farag, and W. S. Moustafa, "Energy performance analysis of integrating building envelopes with nanomaterials," Int. J. Sustain. Built Environ., vol. 2, no. 2, pp. 209-223, 2013. https://10.1016/j.ijsbe.2013.12.001

[26] J. Iwaro and A. Mwasha, "The impact of sustainable building envelope design on building sustainability using Integrated Performance Model," Int. J. Sustain. Built Environ., vol. 2, no. 2, pp. 153-171, 2013. https://https://doi.org/10.1016/j.ijsbe.2014.03.002

[27] B. Succar, "Building information modelling framework: A research and delivery foundation for industry stakeholders," Autom. Constr., vol. 18, no. 3, pp. 357-375, 2009. https://doi.org/10.1016/j.autcon.2008.10.003

[28] M. J. Clayton, P. Teicholz, M. Fischer, and J. Kunz, "Virtual components consisting of form, function and behavior," Autom. Constr., vol. 8, no. 3, pp. 351-367, 1999. https://doi.org/10.1016/S0926-5805(98)00082-X

[29] M. Kassem and B. Succar, "Macro BIM adoption: Comparative market analysis," Autom. Constr., vol. 81, pp. $286-299,2017$. https://doi.org/10.1016/j.autcon.2017.04.005

[30] D.A.: BIM and FM: The Portal to Lifecycle Facility Management. Journal of Building Information Modeling, pp. 13-16, 2010.

[31] Whole Building Design Guide, "Sustainable," available at: https://www.wbdg.org/design-objectives/sustainable, access on Nov, 6, 2017.

[32] V. Holsteijn En Kemna, "Average EU building heat load for HVAC equipment," Delft, 2014. Available at: https://ec.europa.eu/energy/sites/ener/files/documents/2014 final report eu building heat demand.pdf, access on Nov, 6, 2017.

[33] M. Angrick, A. Burger, and H. Lehmann, "Factor X: Re-source - Designing the Recycling Society,” Springer, Netherlands, 2013. 